\title{
Aprendizagem baseada em jogos digitais educativos para o ensino da matemática - um estudo-piloto a partir da utilização do Erudito
}

Recibido: 15 Ago 2016 - Revisado: 30 Sep 2016

Aceptado: 30 Oct 2016 - Publicado: 30 Dic 2016

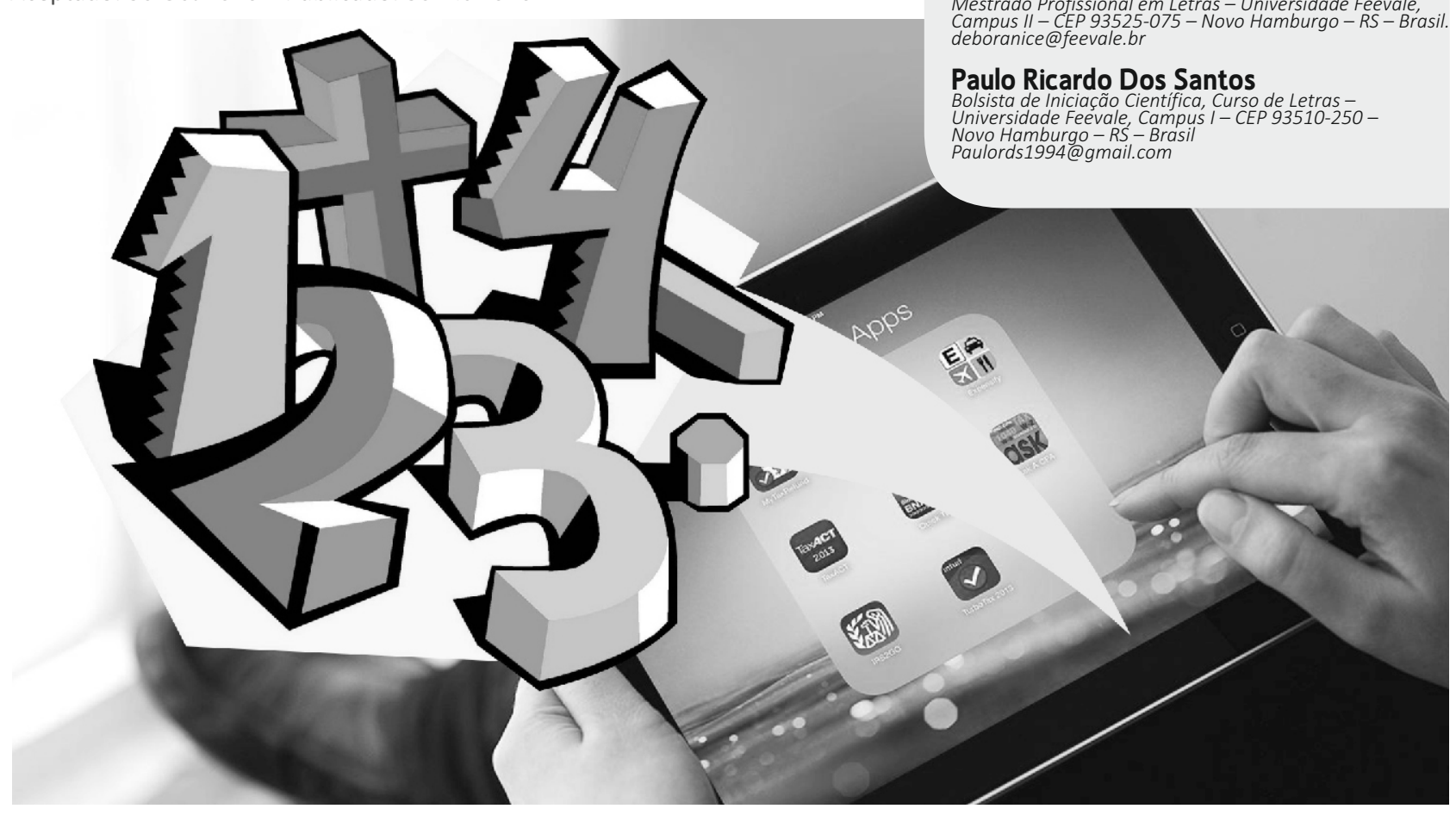

Resumo: A partir da hipótese de que a interação baseada em jogos digitais educativos contribui para a aprendizagem da matemática, este artigo relata a aplicação de um estudo-piloto que associou os jogos digitais educativos, no caso o Erudito, para auxílio no processo de ensino e de aprendizagem da matemática nos anos finais do Ensino Fundamental. A pesquisa realizada caracteriza-se como qualitativa e quantitativa, utilizando-se do método de estudo de caso. Os resultados do estudo-piloto, no qual deu-se o uso de jogos digitais educativos, demonstraram que a utilização dos mesmos pode contribuir na educação como ferramentas de ensino e de aprendizagem, uma vez que permitem ao professor perceber a efetividade de sua prática, podendo avaliar os resultados antes e depois da prática educativa.

Palavras Chave: Jogos digitais educativos. Matemática. Processo de ensino e de aprendizagem

Abstract: From the hypothesis that the interaction-based educational digital games contributes to learning math, this article shows the implementation of a pilot study that associates the educational digital games, in this case the Erudito, to aid in the teaching and learning of math in the final years of elementary school. The research is characterized as qualitative and quantitative, using the case study method. The results of the pilot study, which was given by the use of educational digital games have shown that their use can contribute to education as teaching and learning tools, as they allow the teacher to understand the effectiveness of their practice, being able to evaluate the results before and after the educational practice.

Keywords: educational digital games; math; teaching and learning process. 


\section{INTRODUÇÃOA}

Internet e as tecnologias interativas, vistas como ferramentas para a construção efetiva e significativa do conhecimento, potencializam o ensino e a aprendizagem. Diante da possibilidade da interação e da colaboração, o sujeito não pode mais ser considerado um elemento passivo do seu processo de aprendizagem. Sendo assim, esse sujeito não recebe apenas a informação, mas, a partir da interação oportunizada pelas tecnologias, tem a possibilidade de tornar-se ativo e de interagir com a informação e com outros sujeitos em rede, de modo a construir seu próprio conhecimento. Esses aspectos são importantes, considerando o grupo delimitado para esta pesquisa, cujo perfil é composto por alunos midiáticos, que são aqueles que têm o hábito do jogo digital e possuem muita informação captada pelas TIC, mas sem o aprofundamento do conteúdo disponibilizado, segundo Francisco (2011, p.52). Portanto, para estes, o uso das tecnologias para educar vem a ser um elemento natural. As tecnologias móveis, os jogos digitais educacionais (Mattar, 2010), as redes sociais e as ferramentas da web, em geral, fazem parte do dia a dia dessa geração, também denominada "nativos digitais" (Prensky, 2010).

O uso da computação móvel na educação se situa nesse contexto como um potencializador de novas interações e experiências educacionais. Destaca-se, portanto, a aprendizagem com mobilidade (Saccol et al., 2010) como uma das formas de se adquirir conhecimento e habilidades a partir de práticas pedagógicas e da mobilidade. Parece necessário, portanto, pensar a maneira de se associar as tecnologias móveis e os jogos digitais ao processo de ensino e aprendizagem, uma vez que, na sociedade, a rotina das pessoas está cada vez mais subordinada às "aplicações baseadas nas tecnologias de informação e comunicação (TIC) e, sobretudo, das redes de comunicação que as interligam" (Tic Kids, 2014).
Em meio a esse contexto desafiador, há o interesse pela utilização em dispositivos móveis de jogos educacionais voltados aos conteúdos da matemática, como ferramentas efetivas no processo de ensino e aprendizagem, devido às preocupantes informações veiculadas pela mídia, que mostram resultados escolares aquém do esperado, como a notícia do Jornal Estadão (Saldanha, 2014): “A média de matemática nesta série passou de 243,17, em 2011, para 242,35 em 2013. O valor considerado adequado é 300. Abaixo disso, os alunos não conseguem, por exemplo, analisar uma tabela". Ou seja, não basta corrigir os déficits durante o Ensino Médio ou no 9 으 ano do Ensino Fundamental, aguardando os resultados da Prova Brasil, prova essa que, segundo o INEP, é um instrumento de avaliação que busca analisar o sistema público de ensino e trazer dados para investigar o desenvolvimento das habilidades com relação ao letramento em Língua Portuguesa e Matemática, para constatar se a aprendizagem foi satisfatória em determinados anos de ensino. Portanto, para corrigir os déficits na educação, é necessário prevenir antes, no Ensino Fundamental. Esse é um dos elementos considerados para a escolha dos alunos do 70 ano do Ensino Fundamental como sujeitos desta pesquisa.

Dessa forma, este artigo apresenta os resultados de um estudo-piloto realizado com a aplicação do jogo Erudito, a fim de investigar a aprendizagem baseada em jogos digitais educativos para o ensino da Matemática orientada aos anos finais do Ensino Fundamental. O Erudito é um jogo conhecido como "jogo multiplayer online", ou seja, que tem a particularidade de que pode ser jogado por várias pessoas ao mesmo tempo. É composto por um banco de questões do tipo verdadeiro ou falso, resposta múltipla e escolha única, de ordenação, de texto gratuito, entre outras (Moreno et al, 2012). Essa aplicação teve como objetivo uma análise prévia sobre a utilização de jogos digitais educativos, servindo 
também como experiência na utilização dos jogos em sala de aula. Essa análise prévia serviu para orientar uma pesquisa com intuito de propor uma prática pedagógica que faça uso de jogos digitais educativos e que contribua no processo de ensino e de aprendizagem da matemática.

O artigo está organizado da seguinte forma: No item 1 tem-se a introdução. No item 2, é apresentada a definição sobre o tema e sua potencialidade como estratégia educacional. No item 3, é apresentado o Erudito e os resultados de sua aplicação e, no item 4, apresentam-se as considerações finais.

\section{JOGOS DIGITAIS EDUCATIVOS}

Sabe-se que, historicamente, os jogos educativos vêm sendo utilizados como estratégia de ensino e aprendizagem em matemática. Com o advento das TIC's, passa-se a utilizar também jogos digitais como estratégia de ensino. Os jogos digitais educativos, ou jogos sérios (Mattar, 2010), se inserem em novos contextos de aprendizagem assumindo o seu papel como ferramentas que possibilitam a aprendizagem. Para Mattar (2010), a característica central do jogo é a interatividade, definida pelo mesmo autor (2009, p. 112) como "uma nova maneira de relação do ser humano com as máquinas, eletrônico/digital, distinta da interação (social) e mesmo de outro tipo de interatividade, analógico/mecânica, característico das mídias mais antigas", característica essa que, se retirada, descaracteriza-o como jogo. Para Freitas e Liarokapis (2012), a aprendizagem baseada em jogos educativos impulsiona a inovação através da educação.

Segundo Mattar (2010), a escola separa a aprendizagem do prazer, como se fossem fenômenos mutuamente excludentes: onde há aprendizagem não pode haver diversão. Jogos têm como uma de suas características a sensação de prazer a que os jogadores são submetidos, o que pode provocar um aprendizado involuntário, sem compromisso, sem pressão. Os jogos digitais no processo de ensino e aprendizagem buscam despertar o interesse a partir de uma metodologia envolvente, lúdica e desafiadora. Além disso, procura-se abordar o conteúdo de maneira diferente, favorecendo a tomada de decisões, o raciocínio lógico, a análise de resultados, a revisita aos conceitos e objetivos e a reformulação dos procedimentos praticados durante o jogo. Mattar (2010) também salienta a possibilidade do jogo propiciar o aprendizado através dos erros cometidos, sem gerar frustrações nos estudantes, estimulando novas tentativas.

Do ponto de vista do professor, este deve estar muito bem preparado para exercer seu papel de mediador e atento à importância do planejamento e dos métodos apropriados para a utilização dos jogos digitais. Como qualquer prática pedagógica, a utilização de jogos digitais requer planejamento, tanto pedagógico quanto tecnológico, já que, para sua aplicação ser bem sucedida, os jogadores devem dominar suas regras e estarem cientes do objetivo do jogo e o que suas decisões podem acarretar. Para Santos (2014), o planejamento educacional é primordial como forma de antecipar a ação pedagógica e, com isso, agir de acordo com o preconizado. A mesma autora considera que esse planejamento faz sentido quando o docente está disposto e preparado para mudanças. Neste sentido, parece necessária uma inserção tecnológica para minimizar os problemas enfrentados no ensino da Matemática, visando à melhoria na qualidade de ensino e à ressignificação no processo de aprendizagem dos alunos. A referência (MEC, 2000) mostra que, nos PCNs, “(..) a Matemática deve acompanhar criticamente o desenvolvimento tecnológico contemporâneo, tomando contato com os avanços das novas tecnologias nas diferentes áreas do conhecimento para se posicionar frente às questões de nossa atualidade". 


\section{ERUDITO, APRESENTAÇÃO E AVALIAÇÃO DE RESULTADOS}

O Erudito é um software utilizado como ferramenta para desenvolver ambientes de aprendizagem e, nesta pesquisa, é utilizado para implementação de uma estratégia de ensino e de aprendizagem na construção do conceito de frações e suas operações básicas a partir da utilização das novas tecnologias. 0 Erudito aborda os conceitos matemáticos de uma forma lúdica e nos leva a refletir sobre a aplicação de novas práticas pedagógicas. Na escola escolhida, com base no suporte tecnológico oferecido, o estudo piloto permitiu vivenciar a prática dos jogos digitais educativos e revisar frações, conteúdo explorado pelo Erudito, por meio do acesso aos Desktops, via Internet.

Os alunos foram consultados juntamente com a direção e coordenação pedagógica, que informou aos pais quanto à aplicação e relevância em sala de aula, levando em conta que a instituição oferece recursos tecnológicos e demonstra interesse por inovações nas práticas pedagógicas. O pré-teste foi aplicado sem aviso prévio e o pós-teste foi aplicado após os discentes terem jogado e novamente terem se apropriado dos conceitos trabalhados pelo jogo. Quanto à preparação da turma, explicou-se a proposta e os alunos mostraram-se receptivos à novidade, esclarecendo suas dúvidas com o docente/pesquisador.

O planejamento do material foi desenvolvido com base no trabalho realizado na Colômbia, por meio do uso do Erudito (Moreno et al., 2012), evidenciando que a Matemática está em todas as disciplinas. A prática do jogo Erudito ocorreu no período de três semanas, das quais foram utilizados dez períodos das aulas de Matemática. Para a utilização do Erudito, realizou-se o cadastro dos alunos na rede e cada um recebeu sua senha para acessar o jogo.
A escola escolhida está situada no bairro Hamburgo Velho em Novo Hamburgo, Brasil, sendo uma das quatro maiores instituições de ensino comunitário do município. Quanto ao suporte tecnológico oferecido pela instituição de ensino, a escola está muito bem preparada, já que possui três excelentes laboratórios de informática. Essa mesma escola fará parte das demais etapas da pesquisa.

Nesta etapa do Ensino Fundamental, é estudado o Conjunto de Números Racionais, onde se incluem frações, positivas e negativas. O Jogo Erudito serviu para que os alunos revisitassem esse conteúdo, estudado no ano letivo anterior, excetuando-se as frações negativas, como forma de revisão. Como prérequisito para este conteúdo, é necessário o domínio das operações matemáticas básicas, como conhecimento das suas operações inversas.

A utilização dos referidos jogos em sala de aula requer uma preparação da turma no que se refere à proposta, pois os alunos devem estar receptivos a novidade que será introduzida em suas práticas escolares e cabe ao professor essa tarefa. Na utilização de jogos digitais educativos em sala de aula, o papel do professor é o de orientar e incentivar. Além disso, não se pode ignorar que o conhecimento é construído de forma colaborativa, valorizando a aprendizagem e a realidade do aluno. Também não se pode esquecer as questões tecnológicas, já que, com o Erudito, o professor também orienta o cadastro dos alunos na rede. Durante o período de utilização do jogo, foram realizadas observações para construção da proposta final dessa pesquisa e o pré-teste e pós-teste.

A proposta incluiu a aplicação de pré-teste e pós-teste a fim de verificar o auxílio efetivo do jogo no processo de ensino e de aprendizagem. A análise dos testes foi qualitativa e quantitativa, onde cada questão foi analisada individualmente, relacionando-a ao seu objetivo no processo de ensino e aprendizagem. 
Os resultados dos pré-teste e pós-testes, a partir da aplicação do Erudito, serão utilizados para verificar as potencialidades dos jogos digitais educativos no processo de ensino e aprendizagem em Matemática. Neste momento, serão relatados os resultados de cada uma das questões relacionadas ao seu objetivo específico. Dessa forma, a avaliação permitirá perceber a participação efetiva do aluno, como a utilização dos jogos digitais educativos colabora no processo de ensino e aprendizagem e de que forma esse recurso pode ser utilizado na construção de uma prática pedagógica que associe os jogos digitais educativos e que contribua no processo de ensino e de aprendizagem da matemática.

Na tabela que segue, estão relacionados os objetivos específicos com cada uma das questões do pré e do pós-teste.

Tabela 1. Resultados do Pré-Teste e do Pós-Teste Na Aplicação do Erudito.

\begin{tabular}{|c|c|c|c|}
\hline Objetivos & $\begin{array}{c}\text { Questã } \\
\text { o }\end{array}$ & $\begin{array}{l}\text { Percentual } \\
\text { de acertos } \\
\text { pré-teste }\end{array}$ & $\begin{array}{l}\text { Percentual } \\
\text { de acertos } \\
\text { pós-teste }\end{array}$ \\
\hline $\begin{array}{c}\text { Identificar } \\
\text { leitura de frações. }\end{array}$ & $\begin{array}{l}\text { Questão } \\
1(\mathrm{I})\end{array}$ & $100 \%$ & $100 \%$ \\
\hline $\begin{array}{l}\text { Identificar os } \\
\text { termos de uma } \\
\text { fração. }\end{array}$ & $\begin{array}{l}\text { Questão } \\
1 \text { (III) }\end{array}$ & $84,6 \%$ & $100 \%$ \\
\hline $\begin{array}{l}\text { Identificar os } \\
\text { termos de uma } \\
\text { fração. }\end{array}$ & $\begin{array}{l}\text { Questão } \\
2 \text { (a) }\end{array}$ & $92,3 \%$ & $93,3 \%$ \\
\hline $\begin{array}{c}\text { Identificar } \\
\text { fração imprópria }\end{array}$ & $\begin{array}{l}\text { Questão } \\
1 \text { (II) }\end{array}$ & $92,3 \%$ & $85,7 \%$ \\
\hline $\begin{array}{c}\text { Identificar } \\
\text { números primos }\end{array}$ & $\begin{array}{l}\text { Questão } \\
1 \text { (IV) }\end{array}$ & $76,9 \%$ & $86,7 \%$ \\
\hline $\begin{array}{c}\text { Identificar } \\
\text { números primos }\end{array}$ & $\begin{array}{l}\text { Questão } \\
2 \text { (b) }\end{array}$ & $76,9 \%$ & $93,3 \%$ \\
\hline $\begin{array}{c}\text { Identificar } \\
\text { múltiplos e } \\
\text { divisores de um } \\
\text { número natural }\end{array}$ & $\begin{array}{l}\text { Questão } \\
1(\mathrm{~V})\end{array}$ & $69,2 \%$ & $86,7 \%$ \\
\hline $\begin{array}{c}\text { Identificar } \\
\text { múltiplos e } \\
\text { divisores de um } \\
\text { número natural }\end{array}$ & $\begin{array}{l}\text { Questão } \\
1(\mathrm{VI})\end{array}$ & $92,3 \%$ & $100 \%$ \\
\hline $\begin{array}{c}\text { Identificar } \\
\text { múltiplos e } \\
\text { divisores de um } \\
\text { número natural }\end{array}$ & $\begin{array}{l}\text { Questão } \\
2 \text { (c) }\end{array}$ & $30,1 \%$ & $66,7 \%$ \\
\hline
\end{tabular}

\begin{tabular}{|c|c|c|c|}
\hline $\begin{array}{l}\text { Diferenciar } \\
\text { frações } \\
\text { homogêneas e } \\
\text { frações } \\
\text { heterogêneas }\end{array}$ & $\begin{array}{l}\text { Questão } \\
2 \text { (d) }\end{array}$ & $76,9 \%$ & $86,7 \%$ \\
\hline $\begin{array}{c}\text { Representar } \\
\text { quantidades } \\
\text { relativas } \\
\text { utilizando frações }\end{array}$ & $\begin{array}{l}\text { Questão } \\
3(a)\end{array}$ & $84,6 \%$ & $86,7 \%$ \\
\hline $\begin{array}{c}\text { Representar } \\
\text { quantidades } \\
\text { relativas } \\
\text { utilizando frações }\end{array}$ & $\begin{array}{l}\text { Questão } \\
3 \text { (b) }\end{array}$ & $84,6 \%$ & $86,7 \%$ \\
\hline $\begin{array}{c}\text { Representar } \\
\text { quantidades } \\
\text { relativas } \\
\text { utilizando frações }\end{array}$ & $\begin{array}{l}\text { Questão } \\
9\end{array}$ & $46,1 \%$ & $53,3 \%$ \\
\hline $\begin{array}{l}\text { Comparar } \\
\text { frações }\end{array}$ & $\begin{array}{c}\text { Questão } \\
3 \text { (c) }\end{array}$ & $76,9 \%$ & $53,3 \%$ \\
\hline $\begin{array}{l}\text { Reconhecer } \\
\text { frações } \\
\text { equivalentes }\end{array}$ & $\begin{array}{c}\text { Questão } \\
4\end{array}$ & $69,2 \%$ & $46,7 \%$ \\
\hline $\begin{array}{l}\text { Reconhecer } \\
\text { frações } \\
\text { equivalentes }\end{array}$ & $\begin{array}{l}\text { Questão } \\
5\end{array}$ & $\begin{array}{c}23 \% \\
\text { totalmente e } \\
15,4 \% \\
\text { parcialmente } \\
\end{array}$ & $\begin{array}{c}46,7 \% \\
\text { totalmente e } \\
20 \% \\
\text { parcialmente } \\
\end{array}$ \\
\hline $\begin{array}{l}\text { Efetuar as } \\
\text { operações de } \\
\text { adição e } \\
\text { subtração de } \\
\text { frações com } \\
\text { mesmo } \\
\text { denominador }\end{array}$ & $\begin{array}{l}\text { Questão } \\
6 \text { (a) }\end{array}$ & $30,8 \%$ & $73,3 \%$ \\
\hline $\begin{array}{l}\text { Efetuar as } \\
\text { operações de } \\
\text { adição e } \\
\text { subtração de } \\
\text { frações com } \\
\text { mesmo } \\
\text { denominador }\end{array}$ & $\begin{array}{l}\text { Questão } \\
6 \text { (b) }\end{array}$ & $53,8 \%$ & $80 \%$ \\
\hline $\begin{array}{c}\text { Efetuar as } \\
\text { operações de } \\
\text { adição e } \\
\text { subtração de } \\
\text { frações com } \\
\text { denominadores } \\
\text { diferentes }\end{array}$ & $\begin{array}{l}\text { Questão } \\
6 \text { (c) }\end{array}$ & $7,7 \%$ & $13,3 \%$ \\
\hline $\begin{array}{c}\text { Efetuar as } \\
\text { operações de } \\
\text { adição e } \\
\text { subtração de } \\
\text { frações com } \\
\text { denominadores } \\
\text { diferentes } \\
\end{array}$ & $\begin{array}{l}\text { Questão } \\
6 \text { (d) }\end{array}$ & $7,7 \%$ & $6,7 \%$ \\
\hline
\end{tabular}




\begin{tabular}{|c|c|c|c|}
\hline $\begin{array}{c}\text { Efetuar as } \\
\text { operações de } \\
\text { adição e } \\
\text { subtração de } \\
\text { frações com } \\
\text { denominadores } \\
\text { diferentes }\end{array}$ & $\begin{array}{l}\text { Questão } \\
7\end{array}$ & $\begin{array}{c}7,7 \% \\
\text { totalmente e } \\
46,2 \% \\
\text { parcialmente }\end{array}$ & $\begin{array}{c}66,7 \% \\
\text { parcialmente }\end{array}$ \\
\hline $\begin{array}{c}\text { Efetuar as } \\
\text { operações de } \\
\text { adição e } \\
\text { subtração de } \\
\text { frações com } \\
\text { denominadores } \\
\text { diferentes }\end{array}$ & $\begin{array}{l}\text { Questão } \\
8\end{array}$ & $84,7 \%$ & $80 \%$ \\
\hline $\begin{array}{c}\text { Efetuar as } \\
\text { operações de } \\
\text { adição e } \\
\text { subtração de } \\
\text { frações com } \\
\text { denominadores } \\
\text { diferentes }\end{array}$ & $\begin{array}{l}\text { Questão } \\
9\end{array}$ & $46,1 \%$ & $53,3 \%$ \\
\hline $\begin{array}{c}\text { Aplicar as } \\
\text { operações de } \\
\text { adição e } \\
\text { subtração com } \\
\text { frações em } \\
\text { situações - } \\
\text { problema }\end{array}$ & $\begin{array}{c}\text { Questão } \\
4\end{array}$ & $59,2 \%$ & $46,7 \%$ \\
\hline $\begin{array}{c}\text { Aplicar as } \\
\text { operações de } \\
\text { adição e } \\
\text { subtração com } \\
\text { frações em } \\
\text { situações - } \\
\text { problema }\end{array}$ & $\begin{array}{l}\text { Questão } \\
7\end{array}$ & $\begin{array}{c}7,7 \% \\
\text { totalmente e } \\
46,2 \% \\
\text { parcialmente }\end{array}$ & $\begin{array}{c}66,7 \% \\
\text { parcialmente }\end{array}$ \\
\hline $\begin{array}{c}\text { Aplicar as } \\
\text { operações de } \\
\text { adição e } \\
\text { subtração com } \\
\text { frações em } \\
\text { situações - }\end{array}$ & $\begin{array}{l}\text { Questão } \\
8\end{array}$ & $84,7 \%$ & $80 \%$ \\
\hline $\begin{array}{c}\text { Aplicar as } \\
\text { operações de } \\
\text { adição e } \\
\text { subtração com } \\
\text { frações em } \\
\text { situações - } \\
\text { problema }\end{array}$ & $\begin{array}{l}\text { Questão } \\
9\end{array}$ & $46,1 \%$ & $53,3 \%$ \\
\hline $\begin{array}{c}\text { Aplicar as } \\
\text { operações de } \\
\text { adição e } \\
\text { subtração com } \\
\text { frações em } \\
\text { situações - } \\
\text { problema }\end{array}$ & $\begin{array}{l}\text { Questão } \\
10\end{array}$ & $\begin{array}{c}7,7 \% \\
\text { totalmente e } \\
7,7 \% \\
\text { parcialmente }\end{array}$ & $\begin{array}{c}6,7 \% \\
\text { totalmente e } \\
6,7 \% \\
\text { parcialmente }\end{array}$ \\
\hline
\end{tabular}

Considerando-se as questões analisadas no Quadro 1, dos 27 itens, em 19 (70,37\%) deles houve aumento percentual de acertos, em 1 (3,70\%) o percentual foi o mesmo e em 7 (25,93\%), houve decréscimo. Seguindo na análise quantitativa, simulando-se uma nota de 0 a 10 para os testes pré e pós, a média passa de 5,24, com desvio-padrão 2,078 para 5,89, com desvio-padrão 1,648 , analisando os mesmos 13 alunos que fizeram os dois testes. Considerando-se que não houve intervenção antes da aplicação do pré-teste e que o conteúdo explorado no jogo se referia a conceitos estudados no ano anterior, pode-se afirmar que o jogo contribuiu para a revisão do conteúdo referido, pois houve um aumento percentual de $12,40 \%$ na média da turma.

Para melhor analisarmos estes resultados, aplicou-se o Teste-t de Student para amostras pareadas. O teste pode ser utilizado para compararmos resultados de uma mesma variável em dois momentos distintos, no caso, a média da turma antes e depois da aplicação do jogo. Há que se considerar que o número de sujeitos que compõe a amostra não é adequado, portanto, não é possível inferir o seu resultado para toda uma população.

Tabela 2. Análise estatística do pré-teste e do pós-teste na aplicação do Erudito.

\begin{tabular}{|c|c|c|}
\hline \multicolumn{3}{|c|}{ Teste-t: Duas amostras em par para médias } \\
\hline & Pré-teste & Pós-teste \\
\hline Média & 5,243076923 & $\begin{array}{c}5,88769230 \\
8\end{array}$ \\
\hline Variância & 4,318773077 & 2,717385897 \\
\hline Observações & 13 & 13 \\
\hline Correlação de Pearson & 0,781242031 & \\
\hline Hipótese da diferença de \\
média & 0 & \\
\hline gl & 12 & \\
\hline Stat t & $\mathbf{- 1 , 7 9 1 3 0 1 7 8 5}$ & \\
\hline $\mathrm{P}(T<=t)$ uni-caudal & $\mathbf{0 , 0 4 9 2 3 9 9 0 7}$ & \\
\hline t crítico uni-caudal & $\mathbf{1 , 7 8 2 2 8 7 5 5 6}$ & \\
\hline $\mathrm{P}(T<=t)$ bi-caudal & 0,098479814 & \\
\hline t crítico bi-caudal & 2,17881283 & \\
\hline
\end{tabular}


Com base na amostra selecionada, foi testada a hipótese de que a média dos pré-testes e pós-testes em dois momentos (antes e depois) sofreu alteração (ou não). A hipótese utilizada é do tipo unilateral, isto é, a diferença deve ser para mais. Neste caso temos um teste com as seguintes hipóteses:

$$
\left\{\begin{array}{l}
H_{0}: \mu_{\text {pré-teste }}=\mu_{\text {pósteste }} \\
H_{a}: \mu_{\text {pré-teste }}<\mu_{\text {pós-teste }}
\end{array}\right.
$$

A estatística de teste calculada foi $-1,79$, enquanto que o t crítico (tabelado) foi de 1,78. Outra estatística importante é o valor de apresentando 0,049. Percebese também que a estatística t é superior, em módulo, ao t crítico (tabelado), indicando rejeição da hipótese nula. O valor de $p$-value é inferior ao nível de significância $(0,05)$, também indicando a rejeição de $\mathrm{HO}$.

Com base nos resultados, concluímos pela rejeição de HO. Isso significa que a média do pós-teste pode ser considerada maior do que a média do pré-teste. Alguns objetivos (como, por exemplo, o que se refere à questão $1 /$ II) foram pouco explorados dentro do ambiente jogo. Em outros, mesmo que o percentual seja diferente, como, por exemplo, na questão 10 , houve apenas um aluno que acertou, tanto no pré como no pós-teste. Outro detalhe que foi possível perceber é a maior dificuldade em relação às situações-problema. Durante a utilização do jogo, foi em questões envolvendo situações-problema, semelhantes as aplicadas no pré-teste e no pós-teste, que os alunos mais se cercaram de papel e caneta para solucionarem as mesmas.

Partindo-se desses resultados e considerando que a aplicação do Erudito foi realizada como primeira experiência, tanto pelo professor como pelos alunos, percebeu-se que, na maioria das questões, o jogo contribuiu para uma melhor performance dos alunos em relação aos conceitos trabalhados com frações. Vale salientar que a aplicação do Erudito colaborou na elaboração da proposta pedagógica, objetivo final da pesquisa. No item a seguir, a partir dos resultados obtidos, seguem as considerações finais.

\section{CONSIDERAÇÕES FINAIS}

A proposta de utilização de jogos digitais educativos e das tecnologias em educação é uma alternativa pedagógica que vem sendo amplamente investigada e operacionalizada. O que este artigo relata é a eficácia de um estudo-piloto, com a utilização do jogo Erudito. Esse estudo-piloto serviu para investigar a aprendizagem baseada em jogos digitais educativos e realizar uma análise prévia sobre a utilização desses jogos como ferramenta de aprendizagem em sala de aula. Cabe recordar que essa análise prévia serviu para orientar uma pesquisa com intuito de propor uma prática pedagógica que associe os jogos digitais educativos e que contribua no processo de ensino e de aprendizagem da matemática.

Os resultados da pesquisa, na qual os alunos utilizaram o desktop, apontam que a utilização de jogos digitais educativos, estando os mesmos de acordo com a proposta pedagógica da escola e conciliados com os conteúdos da série onde o jogo está sendo utilizado, favorecem o processo de ensino e aprendizagem.

Os resultados do pós-teste com relação aos do préteste indicaram uma melhora na aprendizagem do conteúdo trabalhado. Aliado a isso, percebeu-se durante o estudo de caso a interação e o espírito colaborativo entre os alunos da turma e a satisfação dos mesmos durante a atividade com o jogo. Essa percepção reforça a ideia a respeito da contribuição da interação baseada em jogos digitais educativos no processo de aprendizagem da matemática.

A partir da comparação das médias do pré-teste e do pós-teste e do resultado do teste estatístico, foi possível concluir que ocorreu a construção do conhecimento a partir da utilização das tecnologias associadas ao jogo digital educativo e quais conceitos 


\section{.. H.'Ingenierías}

foram apreendidos por meio da aplicação da proposta. Esse fato corrobora a contribuição pedagógica da utilização das tecnologias digitais. Igualmente, essas mesmas tecnologias devem ser levadas em consideração pelo enorme potencial que têm em relação à forma com que proporcionam a interação e a cooperação entre os alunos.

Assim, neste artigo, apresentaram-se resultados que discutem um uso das tecnologias que não seja direcionado a substituir métodos tidos como ultrapassados, mas que venha a contribuir como mais uma ferramenta de produção, desenvolvimento e compartilhamento de conhecimento que esteja à disposição tanto do educador como do aluno.

\section{Agradecimentos}

Os autores agradecem ao Conselho Nacional de Desenvolvimento Científico e Tecnológico - CNPq e a Universidade Feevale pelo apoio à pesquisa.

\section{REFERÊNCIAS}

Barbosa, A. (2014). Pesquisa sobre o uso da Internet por crianças e adolescentes no Brasil. TIC Kids Online Brasil 2013 [livro eletrônico]. São Paulo: Comitê Gestor da Internet no Brasil.

Barbosa, D, N. F., Bez, M. R., Mossmann, J. B., Santos, G. N., Strack, T. L., Winter, N. J. (2014). Incentivo ao Estudo Através dos Jogos: experiências no desenvolvimento de uma rede social "gamificada". Hipertexto, 4(3). D i s p o n íve l e m <http://www.bibliotekevirtual.org/revistas/HIPERTEXTO /v04n03/v04n03a01.pdf.> Acesso em: 10 jan. 2015.

Barbosa, D. N. F., Bassani, P. B. S, , J. B. , Schneider, G. T., Reatequi, E., Branco, M. A. A., Meyrer, L. S., Nunes, M. (2014). Mobile Learning and Games: experiences with mobile games development for children and teenagers undergoing oncological treatment. Lecture Notes in Computer Science, 8495, p. 153-164. 2014.

Cardoso, J. (2015). Uma proposta para a utilização de dispositivos móveis orientada as atividades complementares de crianças e adolescentes atendidos pela AMO criança. Dissertação \{Mestrado em Diversidade Cultural e Inclusão Social]. Programa de PósGraduação, Universidade Feevale, Novo Hamburgo, RS. D i s p o n íve I e $\mathrm{m}$ : <http://biblioteca.feevale.br/Dissertacao/DisssertacaoJ anainaCardoso.pdf>. Acesso em: 28 jul. 2015.

Jappur, R. F. (2014). Modelo conceitual para criação, aplicação e avaliação de jogos educativos digitais. Tese [Doutorado em Engenharia e Gestão do Conhecimento\}. Programa de Pós-Graduação em Engenharia de Gestão do Conhecimento, Universidade Federal de Santa Catarina (UFSC), Florianópolis, SC, 2014. Disponível em: <https://repositorio.ufsc.br/xmlui/bitstream/handle/12 3456789/129458/328362. pdf?sequence=1\&isAllowed= y>. Acesso em: 23 nov. 2014.

Letto, F. \& Formiga, M. (2009). Interatividade e aprendizagem. In: Educação a distância, o estado da arte. ABED. São Paulo, SP: Pearson education do Brasil. Disponível em: 
$<$ http://feevale.bv3.digitalpages.com.br/users/publicati ons/9788576051978/pages/_1>. Acesso em: 29 nov. 2014

Levy, P. (1999). Cibercultura. São Paulo: Editora 34. M. Prensky (2010). Não me atrapalhe, mãe - Eu estou aprendendo! São Paulo: Phorte.

M. Prensky (2012). Aprendizagem baseada em jogos digitais. São Paulo: Senac.

M. Prensky (2014). Nativos digitais, imigrantes digitais. Tradução de: Roberta de Moraes Jesus de Souza. Disponível em:

<http://poetadasmoreninhas.pbworks.com/w/file/fetc h / 60222961 / Prensk y \% 20 $\% 20$ Imigrantes\%20e\%20nativos\%20digitais.pdf>. Acesso em: 15 dez. 2014.

Mattar De Mattar, J. (2009). Blog. Disponível em: <http://blog.joaomattar.com/>. Acesso em $15 \mathrm{dez}$. 2014.

Mattar, J. (2010). Games em educação: Como os nativos digitais aprendem. 1 ed. São Paulo: Pearson Prentice Hall. In:

$<$ http://feevale.bv3.digitalpages.com.br/users/publicati ons/9788576055624/pages/_1>. Acesso em: 25 dez. 2014.

MEC (2002). PCNEM+: Orientações Educacionais Complementares aos Parâmetros Curriculares Nacionais. Brasília: MEC.

Moran, J. M. (2007). A educação que desejamos - novos desafios de como chegar lá. Campinas, SP.: Papirus.

Moreno, J., Montano, E. \& Montoya, L. (2012). Creación y monitoreo de video juegos educativos multi-jugador masivos en línea. In: Conferencia Latinoamericana de Objetos de Aprendizaje- Laclo, 7. Guayaquil.

Neto, J. F. B. \& Fonseca, F. S. (2013). Jogos educativos em dispositivos móveis como auxílio ao ensino da matemática. In: RENOTE, 11(1). Disponível em:
<http://seer.ufrgs.br/renote/article/viewFile/41623/26 403>. Acesso em: 20 dez. 2014.

Saldanha, P. (nov., 2014) Alunos do 9o ano pioram em matemática. Disponível em:

<http://educacao.estadao.com.br/noticias/geral,alunos -do-9-ano-pioram-em-matematica,1599632>. Acesso em: 29 dez. 2014.

Santos, L. V. (2014). Planejamento educacional e avaliação. Disponível em:

<http://monitoriadidaticaepratica.blogspot.com.br/201 4/07/planejamento-educacional-e-avaliacao.html>. Acesso em: 10 set. 2015.

Schlemmer, E. (2005). Metodologias para educação à distância no contexto da formação de comunidades virtuais de aprendizagem. IN: Barbosa, R. M. (Org.). Ambientes Virtuais de Aprendizagem. Porto Alegre: Artmed.

Silva, M. G., Gonçalves, N. M. \& Neves, R. B. (2012). A interrelação dos jogos com algumas mídias computacionais: uma forma de potencializar a aprendizagem matemática no espaço escolar na educação de jovens e adultos. Disponível em: <https://www.univates.br/media/egem/XI_EGEM.pdf> Acesso em: 15 jun. 2015.

Silva, T. S. (2012). Jogos sérios em mundos virtuais: uma abordagem para o ensino-aprendizagem de teste de software. Dissertação [Mestrado em computação]. Programa de Pós-Graduação em Informática, Área de Concentração em Computação Aplicada, Universidade Federal de Santa Maria (UFSM), Santa Maria, RS. Disponível em: <cascavel.ufsm.br/tede/tde_arquivos/31/TDE-2013-02$\begin{array}{lllllllllll}0 & 6 & T & 1 & 3 & 5 & 0 & 0 & 0 & Z & -\end{array}$ 3992/Publico/SILVA,\%20TARCILA\%20GESTEIRA\%20DA.p df>. Acesso em: 28 dez. 2014.

Unesco (2014). Diretrizes de políticas para a aprendizagem móvel. 2014. Disponível em: $<$ http://unesdoc.unesco.org/0022/002277/227770por. pdf>. Acesso em: 28 dez. 2014. 